Western University Scholarship@Western

Education Publications

Education Faculty

2013

\title{
Preparing politically savvy principals in Ontario, Canada
}

Sue Winton

York University, SWinton@edu.yorku.ca

Katina E. Pollock

Western University, kpolloc7@uwo.ca

Follow this and additional works at: https://ir.lib.uwo.ca/edupub

Part of the Education Commons

Citation of this paper:

Winton, S., \& Pollock, K. (2013). Preparing politically savvy principals in Ontario, Canada. Journal of Educational Administration, 51(1), 40-54. https://doi.org/10.1108/09578231311291422 


\title{
Title:
}

Preparing politically savvy principals in Ontario, Canada

\section{Authors:}

Sue Winton

York University, Toronto, Ontario, Canada

Katina Pollock

Western University, London, Ontario, Canada

\section{Corresponding Author:}

Sue Winton

Corresponding author's email:

swinton@edu.yorku.ca

\begin{abstract}
About the authors
Sue Winton is an Assistant Professor at York University in Toronto, Ontario, Canada. Her research examines implications of education policy and policy processes for critical democracy.

Katina Pollock is an Assistant Professor at Western University in London, Ontario, Canada. Her research interests include alternative teacher work practices, contingent teacher workforces, formal and informal learning, comparative education policy, and educational leadership and administration.
\end{abstract}

\section{Structured Abstract}

Purpose: We argue that principal preparation programs should help candidates: 1$)$ recognize the political role of the school principal; 2) develop political skills (including the ability to strategically appropriate policy); and 3) understand that the political approach of the principal influences teaching, learning, relationships, governance, and reform efforts. In addition, we report findings of our analysis of Ontario's Principal Qualification Program guidelines to determine if they require principal preparation programs to develop aspiring school leaders' political skills.

Design/methodology/approach: We reviewed theoretical arguments and empirical studies from the fields of school micropolitics, business, educational leadership, and critical policy studies to establish five political skills principals require. We then conducted a content analysis of Ontario's Principal Qualification Program guidelines to determine if they require principal preparation programs to develop aspiring leaders' political skills.

Findings: Ontario's Principal Qualification Program guidelines do not explicitly direct principal preparation programs to help candidates develop political skills. However, the guidelines recognize that principals pursue political goals and work in political 
environments, and they offer opportunities for appropriating the guidelines in ways that promote the development of principal candidates' political skills.

Originality/Value: The paper is the first to analyze Ontario's Principal Qualification Program guidelines to determine if they require principal preparation programs to develop aspiring leaders' political skills. It also identifies policy appropriation as a political skill that should be developed in principal preparation programs and provides a model of how principal preparation policies themselves may be appropriated to support a focus on developing aspiring principals' political skills.

Key Words: principal preparation; Ontario; policy

Article Classification: Empirical paper 
What makes a school principal successful? Implementing provincial mandates faithfully? Raising students' test scores? Working with school communities towards more socially just schools and communities? While answers to this question vary, achieving any conception of school success requires that principals use political skills and knowledge of their political environment in their efforts. How principals act politically impacts teaching, learning, change efforts, school governance, relationships, and democracy in education (Blase and Anderson, 1995; Blase and Blase, 2002b; Malen and Cochran, 2008; Malen and Ogawa, 1988; Ryan, 2010). Most principals acquire their political skills on the job, often through mistakes (Crow and Weindling, 2010; Ryan, 2010). Indeed, the political aspect of principals' work is often overlooked in principal preparation programs (e.g., Blase and Blase, 2002b; Crow and Weindling, 2010), and a cursory review of the literature finds only a few studies that consider if and how aspiring school leaders learn political skills (e.g., McGinn, 2005).

We, like others before us (Blase and Blase, 2002b; Crow and Weindling, 2010; Fink, 2005; Starr, 2011), call for principal preparation programs to develop aspiring leaders' political skills. Recognizing that the same political strategies can be used to achieve vastly different goals, our commitments to equity and social justice lead us to encourage those who prepare principals to help aspiring school leaders understand how their work in schools can challenge inequities in society and how they can use their political skills to promote democracy in education. In this paper we explore how these goals may be achieved in Ontario, Canada, within the province's legal and policy frameworks. In so doing we contribute to the dearth of studies that examine principal preparation in the province (for exceptions see Begley and Cousins, 1990; Smith, 2010; Zaretsky, 2003). 
We begin by reviewing findings from research on school micropolitics that demonstrate that the principals' role is inherently political and, further, that how the principal acts politically affects almost every aspect of school life. We highlight political skills principals use to challenge and/or promote the status quo in their work. Next, we describe the process of principal preparation in Ontario, Canada, and analyze the Principal's Qualification Program (PQP) guidelines that inform principal preparation programs in the province. We show that the PQP guidelines do not explicitly require the development of aspiring school leaders' political skills in principal preparation programs. However, we demonstrate how the PQP guidelines can be appropriated to support a focus on developing principal candidates' political skills. We conclude with a discussion of the implications of our analysis and recommendations for principal preparation programs in Ontario and beyond.

\section{Political nature of principals' work}

Schools are political organizations (Ball, 1987; Bjork and Blase, 2009; Blase and Anderson, 1995; Blase and Blase, 2002b; Malen and Cochran, 2008), and the role of a school principal is inherently political (Anderson, 2009; Cuban, 1988). According to Young et al. (2008), "politics, broadly conceived, may be defined as the way each of us, whether individually or working with others, tries to make the kind of school, community, or society we want to have" (p. 70). Politics involve choices (often conflicts) about how to distribute power, opportunities, wealth, and other social goods based on values and the processes used to determine those outcomes (Kirst and Wirt, 2009; Young et al., 2008). Public education is itself inherently political because it involves choices about how to organize schools, what knowledge to examine, and which goals to pursue. Principals act politically in multiple spheres: global; societal, community; district; and school (Matthews and Crow, 2003 in Crow \& Weindling, 2010; 
Cuban, 1988). Ontario principals operate in complex environments characterized by increasing cultural and economic diversity, demands for public accountability, changing technology, and numerous, often competing, political goals from the provincial government (Normore, 2004). For example, they are called to administer standardized tests in the name of accountability that have been critiqued for perpetuating inequities (e.g., see Ricci, 2004) while simultaneously demonstrating "a commitment to establishing a just, caring society” as part of Ontario’s Equity and Inclusive Education Strategy (Ontario Ministry of Education, 2009b, p. 10). How principals act in schools can challenge or perpetuate inequities that exist in other spheres (Anderson, 2009; Ryan, 2010).

We begin this section with a brief review of research primarily from the field of school micropolitics to demonstrate the political nature of principals' work in schools. We then draw on the fields of business, educational leadership, school micropolitics, and critical policy studies to identify five complimentary types of political skills principals need to possess; they need to be able to 1) persuade others; 2) bargain and negotiate; 3 ) build networks and develop coalitions; 4) understand their political terrain; and 5) appropriate policy. We discuss a few studies in detail that are unique in their focus on how principals use their political skills to promote democracy in education or to appropriate policy.

The field of micropolitics is concerned with "the use of formal and informal power by individuals and groups to achieve their goals in organizations" (Blase, 1991b, p. 11). Research on school micropolitics aims to understand the day-to-day life in schools and the strategic use of power to influence others and protect themselves (Blase, 1991b). Although politics are often viewed negatively, micropolitical actions and processes may be cooperative and consensual as well as conflictive (Bjork and Blase, 
2009; Blase and Blase, 2002b). They may be undertaken consciously or unconsciously (Blase and Blase, 2002b). Studies have examined the political strategies of and interactions between principals and teachers (e.g., Blase and Blase, 2002a; Marsh, 2012), superintendents (e.g., Bjork and Blase, 2009), parents (Malen and Cochran, 2008; Malen and Ogawa, 1988) and students (Blase and Anderson, 1995). How principals act politically impacts teaching, learning, change efforts, school governance, and relationships (Blase and Anderson, 1995; Blase and Blase, 2002b; Malen and Cochran, 2008; Malen and Ogawa, 1988; Ryan, 2010).

Various micropolitical leadership approaches have been proposed to capture the different political strategies and goals of school principals. Blase and Anderson (1995), for example, present a matrix of micropolitical leadership. On the horizontal axis of their matrix lie two dimensions of micropolitical leadership style: open and closed. At the closed end of the continuum are principals who wield power in more direct ways. At the open end, principals use more diplomacy and wield power more indirectly. At the two ends of the matrix's vertical axis lie transactional and transformative goals. Principals with transformative goals are concerned with challenging the status quo in schools and society, whereas those with transactional goals are less concerned with broader societal issues. From this matrix emerge four types of micropolitical approaches to school leadership: authoritarian (closed-transactional); adversarial (closed-transformative); facilitative (open-transactional) and democratic, empowering (open-transformative).

The micropolitical approach of principals affects their relationships with teachers; teachers' relationships with students and each other; teachers' classroom performance; and the school as a whole (Blase and Anderson, 1995). For example, 71\% of teachers with authoritarian principals report the political actions of their principal negatively affected their classroom performance including lowering their morale and making it 
difficult for teachers to make decisions they felt appropriate for their classrooms. Teachers report sometimes taking out their frustration on the students. Authoritarian leaders create school climates characterized by distrust, fear, and avoidance. Direct tactics used by authoritative principals to control teachers include using resources, working conditions, opportunities to influence decisions, support, and performance evaluations as sanctions and rewards. Indirect tactics include limiting access to superiors, managing the principal's approachability and emphasizing differences in authority between the teachers and principals. In response, teachers report using protective, reactive and nonthreatening strategies to achieve protective goals including avoidance, ingratiation, and rationality (Blase, 1991a). Teachers working with open principals, on the other hand, are less concerned with protective or reactive protective strategies and much more likely to report using diplomacy, visibility, and extra work as political strategies (Blase and Anderson, 1995).

Blase and Anderson's (1995) work highlights the significance and variety of strategies principals use to influence others. Additional strategies designed to influence others identified in research on school micropolitics and educational leadership include controlling meeting agendas and decision-making processes; co-optation; buffering; listening; diplomacy; humour; strategic use of data; using rewards and sanctions; and avoidance (Blase and Anderson, 1995; Crow and Weindling, 2010; Malen and Ogawa, 1988; Marsh, 2012). Ryan's (2010) study of inclusive/equity-minded principals in Ontario demonstrates how these principals use micropolitical strategies to promote democratic goals. The political strategies they report include persuading others, being honest, persisting, planning, experimenting, keeping others off-balance, playing ignorant, working the system, and quietly advocating. Strategies for persuading others include circulating information, guiding discussions, provoking, asking critical questions, 
encouraging discussion, preaching, using language carefully, complimenting superiors, and using government language. Many of these strategies enable agenda-setting, one of the "key skills" of effective politicians described by Bolman and Deal (2008). Agendasetting involves developing a change agenda and a plan for achieving it.

Bolman and Deal (2008) also identify the ability to build networks and coalitions and to bargain as two important political skills of organizational leaders. Developing coalitions requires developing relationships with others who can help managers (in this case, principals) achieve their goals. Principals in Ryan's (2010) study discuss the importance of developing relationships and looking out for allies in their efforts to promote inclusion and social justice, while principals interviewed by Fraatz (1989) explain they must rely on bargaining and persuasion in their efforts to change teachers' attitudes and improve instruction.

A fourth kind of political skill principals require is the ability to read their political environment and act strategically to determine which tactics to use, when, and with whom (Ryan, 2010). Ryan (2010) refers to this skill as possessing political acumen, and Bolman and Deal (2008) call it "mapping the political terrain" (p. 216). For principals in Ryan's (2010) study understanding their political environment involves knowing about various people in the school system, learning and understanding the system's conventions and priorities, and getting to know the school community and staff. Strategies for acquiring this knowledge include listening, interacting with people, sitting on board-wide committees, moving from board to board, and utilizing focus groups and surveys. With this knowledge principals then work to establish and develop relationships and persuade others. Principals interviewed by McGinn (2005) in Alberta, Canada, expressed their belief that principals need to possess some level of political acumen to be successful and that this need was becoming more important in their work. They also 
asserted that principal preparation programs can and should help aspiring principals develop political acumen, although their preparation did not do so (McGinn, 2005).

The final political skill we discuss here is policy appropriation. Policy appropriation involves making sense of district and provincial policy mandates and determining how they will be enacted at the school level (Spillane et al., 2002). This inevitable process is also viewed as policy implementation (Honig, 2006) or enactment (Ball et al., 2012) depending upon one's beliefs and assumptions about policy processes. Traditional conceptions of public policy view policy as a decision made by an authoritative body such as a group of elective officials and/or government. Decisions are written down in texts and handed down to a different group of people, policy implementers, who implement the decision in their workplaces. From this perspective, policymakers in the field of K-12 education are governments and school districts and policy implementers are school administrators and teachers.

The recognition of educators' agency with regards to policy is an important aspect of critical approaches to education policy studies. Ball (1994), for example, argues that everyone who encounters policy texts remakes them through their beliefs, goals, and histories. Similarly, Levinson et al. (2009), Anderson (2009), and Koyama (2011) discuss policy appropriation rather than implementation; policy appropriation is "creative interpretative practice" that occurs when "a policy that was formed within one community of practice meets the existential and institutional conditions that mark a different community of practice" (Levinson et al., 2009, p. 782). In other words, policy created in one place (e.g., school district, provincial government) is remade by those who encounter it someplace else (Levinson et al., 2009).

Whether considered appropriation, interpretation, enactment, or implementation, principals inevitably have to determine how external mandates will be handled in their 
schools. This can be challenging work in part since policy directives are often vague and change over time. Further, language used in policy texts often has multiple possible meanings; while this may sometimes be confusing it also creates opportunities for principals to interpret policy texts in ways that support their goals. Finally, policies advantage some groups while simultaneously disadvantaging others. How principals and school communities appropriate policies can perpetuate or challenge the status quo (Anderson, 2009).

There are few studies that examine principals' responses to external policies from the lens of policy appropriation. However, in a unique study Koyama (2011) demonstrates how principals appropriated mandated supplementary educational services (SES) policy in New York City Public Schools to achieve their goals. Some principals created low demand for SES by providing concurrent programs run by the school or limiting the number of classrooms available to SES providers. By limiting demand, these principals took advantage of a policy provision permitting reduced spending on SES. Some principals offered incentives (i.e., increased student enrolment) to SES providers who would accommodate the schedules of community-based organizations in the schools, while other principals threatened not to renew contracts with providers if they did not adjust their programs to reflect the schools' staff, structure, curriculum, and instruction. Koyama (2011) concludes that the "[p]rincipals, through their interactions with other policy actors, enacted creative and practical management of problems constituted by the uncertainties of the policy" (p. 33).

The study by de Jong et al. (2005) regarding three school districts' interpretation of new English-only legislation in Massachusetts provides another example of policy appropriation by educational leaders. Three district administrators with commitments to helping students maintain their first languages and expertise in bilingual education were 
faced with implementing new "English-only" legislation in their districts. Wanting to preserve what they believed to be sound academic practice, they strategically appropriated the legislation in ways that enabled them to follow the law and continue to offer students access to their first languages. For example, they interpreted vagueness in the policy which stated that teachers could use "a minimal amount of the child's native language when necessary" (de Jong et al., 2005) to mean that they could use the students' first language to support their learning (e.g., to explain vocabulary and new concepts). Further, while the law required the use of English language textbooks, the district continued to use support materials in the children's first languages. They also clustered students with the same first language in the same English-only classes so students could provide support to one another in their first language. The authors conclude "it is crucial that district leaders make themselves experts on details of the law so that they can not only understand its limitations but also utilize its opportunities for their district" (de Jong et al., 2005, p. 466).

Taken together, studies of school micropolitics and policy appropriation demonstrate: 1) principals' work is inherently political; 2) principals need political skills to accomplish their goals; and 3) achieving the ideals of equity and inclusion requires that principals know how to use their political skills as part of their efforts. How do principals develop their political skills? Political aspects of principals' work are often overlooked in principal preparation (Crow and Weindling, 2010). We turn now to investigate how and in what ways (if any) principal preparation guidelines in Ontario, Canada, recognize the political nature of principals' work and suggest approaches to develop aspiring leaders' political skills and acumen.

\section{Principal preparation in Ontario, Canada}


In Canada each province and territory is responsible for governing and providing free education to its citizens. Ontario is the country's most populous and diverse province, and its four public school systems serve over 2 million children in nearly 5000 schools (Ontario Ministry of Education, 2010). Ontario has four publically funded school systems: French Catholic; English Catholic; English public (i.e., non-Catholic) and French public. The Ontario College of Teachers (the regulating and governing body of teachers in Ontario) governs principal preparation and certification in the province. To become certified as a principal in Ontario a teacher must have five years teaching experience, qualifications in three divisions (primary, junior, intermediate, and/or senior level), a master's degree (in any area) or two specialists (concentrations) or one specialist and half a master's degree, and complete the Principal Qualification Program (Ontario College of Teachers, 2009). A variety of providers, including universities, a teacher union, the Ontario Principals' Council, and the Catholic Principals' Council of Ontario offer the Principal Qualification Program (PQP). The PQP has three components: Part 1 and Part 2, which involve 100 hours of classroom instruction and 25 hours of independent study each, and a 60 hour leadership practicum (Ontario College of Teachers, 2009).

The PQP is rooted in the five domains of Ontario's Leadership Framework (Ontario College of Teachers, 2009) which is part of the province's Leadership Strategy. The Ontario Leadership Strategy was introduced in 2008 "to foster leadership of the highest possible quality in schools and school boards" (Ontario Ministry of Education, 2009a). The first part of Ontario's Leadership Framework identifies five domains of leadership for school-level leaders: 1) setting directions 2) building relationships and developing people; 3 ) developing the organization to support desired practices; 4) improving the instructional program; and 5) securing accountability. A sixth domain, 
Catholic Faith, Community, and Culture, makes up part of the Leadership Framework for leaders in Catholic schools and districts. Leadership practices and competencies (including skills, knowledge, and attitudes) associated with each of these domains are identified for principals, vice-principals, and supervisory officers. Practices are the "actions, behaviours, and functions found through research and professional experience to have a positive impact on student achievement" (The Institute for Education Leadership, 2008, p. 3).

Principal preparation in Ontario is based on the five leadership domains of the Leadership Framework. The PQP guidelines (Ontario College of Teachers, 2009) state what aspiring leaders' are expected to learn and understand related to each domain in the two classroom-based parts of the preparation program. The vision for principal preparation is that "Candidates in the program will develop knowledge, skills and attitudes that build their personal and professional capacity to collaboratively set direction, develop meaningful relationships, promote the growth and development of others, lead the instructional program, develop and manage the school and ensure accountability for all stakeholders" (Ontario College of Teachers, 2009, p. 1).

\section{Analyzing the Principal Qualification Program (PQP) guidelines}

We analyzed the PQP guidelines to determine if principal preparation programs in Ontario are required to help candidates develop their political skills. The guidelines are published in the text Principal Qualification Program Guideline 2009 (Ontario College of Teachers, 2009). This text contains lists of learning expectations for principal candidates and content to be addressed in principal preparation programs. It is important to examine policy texts because they are not only textual efforts to influence practice but also discourses that shape and constrain possibilities for thinking, speaking and acting (Ball, 1994). Discourses construct what it means to be a certain kind of subject, such as a 
school principal, by establishing what is possible and impossible (MacLure, 2003). Ball (1994) explains that "the effect of policy is primarily discursive, it changes the possibilities we have for thinking 'otherwise"' (p. 23). Thus, our analysis of the PQP guidelines will illuminate how, as discourse, they contribute to the construction of what it means to be a principal in Ontario.

Our analysis began with establishing a set of codes (Miles and Huberman, 1994) that reflect the five political skills identified in our literature review. The starting codes were: persuading others; bargaining/negotiating; building alliances/networking; mapping terrain; and policy appropriation. We began by reading the guidelines multiple times and looking for phrases that explicitly referred to any of these five skills. None were identified. Next, recognizing that principal preparation providers will appropriate the PQP guidelines, we highlighted phrases that could be interpreted as advocating that principal candidates learn political skills through the PQP. Highlighted phrases were placed in codes named for the political skill they might address. For example, "various theories, models and strategies for effective decision making and problem solving" (p. 4) and "strategies to promote individual and team development" (p. 5) were coded as persuading others. The expectations that candidates would explore "the dynamics and influences of power and privilege upon school culture" (p. 5) and "identifying, analyzing and responding to factors that impact upon and influence school improvement" (p. 6) were coded as mapping the terrain.

New codes were created throughout the analytic process that reflected aspects of educational politics not captured in the start codes. For example, the guidelines identify many policies and legislation that candidates must understand. We created a new code (policy work) for referencing various ways principals engage with policy. This code was divided into subcategories to distinguish between data referring to knowledge about 
existing policies (e.g., international and provincial testing programs, Ontario Leadership Framework), policy appropriation (e.g., strategies to connect goals and align school planning processes with board and ministry directions, current learning theories, and school effectiveness research"; p. 7), and policy development (e.g., "leadership in curriculum management, review, development and implementation"; p. 4). The code political goals was created to capture various goals principal candidates are expected to learn to pursue (e.g., "build and sustain learning communities that support diversity and promote excellence, accountability, anti-racism, equity, partnerships and innovation"; $p$. 5). Finally, the code political environment was created to capture phrases that suggested that principal candidates learn how to work in political environments (e.g., "the role of the local union and school union representative(s)" (p. 6) and "the political context of education"; p. 4). The qualitative data management software program HyperRESEARCH was used to facilitate organization of data throughout this analytic process. We turn now to a discussion of our findings.

\section{Political skills and PQP curriculum}

The PQP guidelines do not explicitly direct principal preparation program providers to help candidates develop political skills. However, the guidelines implicitly recognize that principals pursue political goals and work in political environments, and they offer opportunities for appropriating the guidelines in ways that promote the development of principal candidates' political skills.

The expectation that candidates will be able to "build and sustain learning communities that support diversity and promote excellence, accountability, anti-racism, equity, partnerships and innovation" (p. 5), for example, alludes to the principal's role in the pursuit of multiple political goals. More specifically, expectations that candidates will learn how to "foster an open, fair, equitable culture through fostering anti- 
discriminatory, anti-racist practices and principles" (p. 5), "use communication strategies to address barriers and engage marginalized members of the community" (p. 5) and understand "diversity and equity at all levels of the organization to ensure equity of access to opportunity and achievement for staff and students" (p. 6) reflect the Ontario Ministry of Education's stated commitments to equity and inclusive education (Ontario Ministry of Education, 2009b).

The political environments in which principals work and their role in policy processes are addressed in the expectations that candidates "understand and apply education and student-related legislation in Ontario and district school board policies that have an impact on the school, students, staff and community" (p. 6) and "demonstrate accountability for the achievement of all students" (p. 8). Further, the expectation that PQP candidates will be able to "initiate, facilitate manage change, and operate successfully in a dynamic environment characterized by increasing complexity" (p. 4) recognizes that principals' work involves addressing numerous demands and changing schools, an inherently political goal (Young et al., 2008).

A number of PQP content expectations also recognize the multiple spheres in which principals engage politically and create opportunities for candidates to learn about political environments at various levels. For example, candidates are expected to explore and understand "labour relations, collective agreements, the role of the local union and school union representative(s), and grievance procedures" (p. 6). They need to learn about "provincial, national and international testing programs" (p. 8), and "how to positively portray the school in the community" (p. 6).

While the program expectations and some content expectations address political goals and environments in which principals work, the PQP guidelines do not clearly state that principal candidates should learn political skills as part of their leadership programs. 
The few references to program content in the guidelines that correspond to political skills and strategies identified by working principals or in the research literature are not discussed in terms of their possible political functions. For example, one of the principals in Ryan's (2010) study said s/he circulated student achievement data as a way to persuade educators; the PQP guidelines say only that principals should know how to use data to "understand and assess the needs of the school" and to "improve student achievement" (p. 8). Similarly, the term "network" appears only once in the PQP guidelines where it states in Part 1 that candidates explore "support networks and role of professional organizations" (p. 5). How networks serve principals politically is not discussed. The PQP guidelines do not state anywhere that candidates should explore or understand how to bargain, negotiate, appropriate policy, or map their political terrains.

At the same time, however, the PQP guidelines include many general statements that can be interpreted as endorsing the development of candidates' political skills. There are many references to "strategies" and "practices" that candidates should learn to achieve various goals that could include strategies for persuading others, bargaining and negotiating, and developing networks and coalitions. For example, the guidelines expect candidates to explore and understand "strategies for resolving ethical dilemmas" (p. 5), "various theories, models and strategies for effective decision making and problem solving" (p. 4), "strategies to build, communicate and implement a shared vision" (p. 4), "strategies to develop a school culture which promotes shared knowledge and shared responsibility for outcomes" (p. 6), and "practices to create and enhance professional relationships and promote capacity building" (p. 5). The ability to implement a vision and change teachers' attitudes and behaviours depends in part on principals' ability to persuade and negotiate (Bolman and Deal, 2008; Fraatz, 1989). 
In addition, principal candidates are expected to explore "conflict management and mediation" (p. 5), "giving and receiving feedback" (p. 5), and "working with school councils" (p. 6), as well as understand "the political context of education" (p. 4).

Discussions of any of these topics in principal preparation programs could incorporate lessons about how to use various political strategies and map the political terrain of schools, communities, and districts.

The PQP guidelines also recognize that principals engage in a lot of policy work. Principal candidates are expected to understand the requirements and expectations of legislation and numerous provincial and district policies related to special education, safe schools, student records, attendance, negligence, testing programs, labor relations, report cards, budgeting processes, Ontario’s Leadership Framework and others. Candidates are also expected to know how to apply legislation and implement "core ministry and board priorities" (p. 7). The PQP guidelines do not, however, acknowledge that external policies must be appropriated to fit the different realities of each school (Levinson et al., 2009) nor do they require candidates to learn strategies for appropriating policies in ways that satisfy local, district, and provincial demands. Instead, the guidelines, as discourse (Ball, 1994), construct the principal as primarily an implementer of external policy rather than one who appropriates it. They also ignore the reality that individuals and groups in schools do not always share ministry and district goals, and that principals have to find ways to manage these conflicts. Instead, they recreate traditional conceptions of policy processes as rational and linear.

Principals are constructed as possible policy makers within the realms of curriculum and school planning, however. The guidelines state candidates should understand "leadership in curriculum management, review, development and implementation" (p. 4). The guidelines also recognize that principals develop local plans 
as part of "leading the instructional programs", and they require that candidates understand "strategies to connect goals and align school planning processes with board and ministry directions, current learning theories, and school effectiveness research" (p. 7). This content expectation creates an opportunity for PQP providers to introduce candidates to "strategies" for policy appropriation and to help candidates understand that appropriating policy is inevitable and complex.

There are other opportunities for PQP providers to interpret the guidelines as supporting efforts to teach candidates about policy appropriation. For example, candidates are required to explore "strategies to build, communicate and implement a shared vision" and "strategic planning and processes that engage the diversity, values, and experiences of the school community, and district school boards" (p. 4). Meetings to discuss how to appropriate external policy mandates with teachers, staff, and parents and community members can be presented as one such strategy. Another might be looking for support in official policy texts to implement local goals, similar to the actions of educational leaders in de Jong et al.'s (2005) study so their districts could continue to offer bilingual education within the parameters of English-only legislation. Candidates can also be shown how they might purposefully define words with multiple meanings in official texts (e.g., democracy, critical) in ways that support local goals. Thus, while the PQP guidelines do not explicitly state that candidates should appropriate policy and strategies to satisfy multiple and sometimes competing demands, $\mathrm{PQP}$ providers can appropriate the guidelines in ways that will support their efforts to prepare candidates for this aspect of principals' policy work.

\section{Implications for principal preparation in Ontario and beyond}

The PQP guidelines ground principal preparation in Ontario. Since the guidelines do not state explicitly that aspiring principals should learn political skills, 
principal preparation programs must interpret them in ways that ensure candidates develop these skills as part of their leadership education. If principal educators fail to do so, principals will be left to acquire political skills on the job, often through mistakes (Crow and Weindling, 2010; Ryan, 2010). This is a risky proposition since, as discussed above, the political approach of the school administrator is the most important determinant of the micropolitics of the school culture. A school's micropolitical culture, in turn, affects teaching, learning, relationships, and change efforts (Blase and Blase, 2002b). For example, if teachers perceive the principal as unsupportive, teachers are likely to be defensive and cautious when dealing with parents (Blase, 1987). They may also displace their frustration and hostility on students (Blase and Anderson, 1995). On the other hand, if teachers perceive their principal to be supportive, teachers' interactions with parents are more likely to be rational, honest, and productive (Blase and Anderson, 1995).

Furthermore, the realization of many of the Ontario Ministry of Education's goals depends on principals' political skills. One of the government's priorities in education is high student achievement (Ontario Ministry of Education, 2012). Ontario’s Leadership Framework (The Institute for Education Leadership, 2008) identifies five domains of principal practices linked to achieving this goal: setting directions; building relationships and developing people; developing the organization; leading the instructional program; and securing accountability. The domain Setting Directions states that "the principal builds a shared vision" and ensures it "is clearly articulated, shared, understood and acted upon by all" (The Institute for Education Leadership, 2008, p. 10). Creating a vision and developing a plan to realize it involves understanding one's political terrain; realizing the vision involves creating networks, developing coalitions, bargaining, and negotiating (Bolman and Deal, 2008). Ontario's Leadership Framework also expects principals to 
improve teachers' instruction; doing so requires persuasion and negotiation (Fraatz, 1989). In addition, Ontario's Ministry of Education's Equity and Inclusive Education Strategy (Ontario Ministry of Education, 2009b) calls on schools "to create and support a positive school climate that fosters and promotes equity, inclusive education, and diversity" (p. 11). Ryan's (2010) research demonstrates that "[i]f principals are to succeed in their social justice endeavours, then they have little choice but to play the political game, that is, to acknowledge the political realities of their organizations, hone their political skills and put these skills into play. Failure to do so will not bode well for the future of equity and social justice" (p. 374).

An important political skill for principals committed to equity, inclusion, and diversity to possess is strategic policy appropriation. This may include the ability to find support in official policy documents for pursuing goals not explicitly stated in those texts. For example, Ontario's Character Development Initiative (Ontario Ministry of Education, 2009/2011) advocates a predominantly traditional approach to character education; however, close reading of official documents finds they can also be interpreted as supporting activities more in line with critical democratic commitments to equity, diversity, and social justice (Winton, 2010).

As part of their focus on policy appropriation principal preparation programs should introduce aspiring leaders to competing conceptions of policy (i.e., rational/technical vs. critical conceptions) and the assumptions that underlie them so candidates can determine how they will position themselves in relation to top-down mandates and policy processes. Conceptualizing policy from a critical perspective requires that candidates understand how economic, political, geographical, social, and historical contexts affect how policies are appropriated (consciously or unconsciously) at the local level. It also requires that candidates see themselves as policy actors and 
recognize their action (or inaction) may challenge or perpetuate inequities beyond school walls. Ozga (2000) argues that engaging with policy in this way is a professional responsibility of educators and contributes to democracy in education.

Including political skill development in principal preparation programs may also help principals keep their jobs. Davis (1998) asked superintendents in California to identify the top 5 reasons principals are dismissed. The superintendents identified principals' inability to build positive relationships, manage diverse political demands, build a strong base of support, and establish trust and confidence as well as their failure to make good decisions and judgments. All of these reasons reflect principals' lack of political skills. Explicit discussion and preparation for the political aspects of principals' work may help principals be successful and retain their positions.

Finally, the PQP guidelines require that principal candidates review theories of leadership. Principal educators should introduce leadership theories that recognize the political nature of principals’ work. For example, Anderson’s (2009) advocacy leadership is a theory that explicitly discusses policy appropriation as a political strategy and views the principal as an advocate for his/her school and community. Advocacy leaders are committed to democracy, equity, and including families and communities in decision-making. They recognize that many government policies reinforce the status quo, and they work with their local communities to appropriate policies. Principal preparation programs can encourage candidates to compare leadership theories and research that explicitly recognize political aspects of principals' work and how people in schools use political skills to achieve their goals in light of policies and theories that construct principals as politically neutral policy implementers and ignore the complex political reality of life in schools. 
Future research should examine principal preparation programs in Ontario and investigate how the PQP and other policies are enacted. Unlike in the USA, principal preparation has not been a focus of investigation in Ontario or across Canada more broadly. Exceptions include leadership preparation for special education (Zaretsky et al., 2008) and Canadian contributions to the International Study of Principal Preparation (ISPP). An ISPP study of new principals trained in Alberta, Canada, and South Africa recommends that leadership preparation focus more on relationships and people skills than organizational aspects of the school (Mentz et al., 2010).

We close by answering, in part, the question we posed in this article's first sentence: what makes a school principal successful? A successful principal is one who possesses political skills and acumen and understands that how s/he acts politically affects teaching, learning, relationships, school governance, change efforts (including those aspiring to critical democracy), and his/her career (Blase and Anderson, 1995; Blase and Blase, 2002b; Davis, 1998; Malen and Cochran, 2008; Malen and Ogawa, 1988). Thus, all principal preparation programs, not only those in Ontario, must help principal candidates become comfortable and effective in their political role because their success as school leaders -- and the success of the students, families, teachers, and communities with whom they work -- depends on it. 


\section{References}

Anderson, G.L. (2009), Advocacy Leadership: Toward a Post-Reform Agenda in Education, Routledge, New York.

Ball, S.J. (1987), The Micro-Politics of the School: Towards a Theory of School Organization, Routledge, New York.

Ball, S.J. (1994), Education Reform : A Critical and Post-Structural Approach, Open University Press, Buckingham [England], Bristol, PA.

Ball, S.J., Maguire, M. and Braun, A. (2012), How Schools Do Policy: Policy Enactments in Secondary Schools, Routledge, New York.

Begley, P.T. and Cousins, B.J. (1990), "The pre-service preparation of school administrators: a description and assessment of the OISE program", paper presented at the Annual Meeting of the Canadian Society for Studies in Education, University of Victoria, Victoria, BC, June.

Bjork, L. and Blase, J. (2009), "The micropolitics of school district decentralization", Educational Assessment, Evaluation and Accountability, Vol. 21 No. 3, pp. 195208.

Blase, J. (1991a), "The micropolitical orientation of teachers towards closed school principals", Education and Urban Society, Vol. 23 No. 4, pp. 356-378.

Blase, J. (1991b), "The micropolitical perspective", in Blase J. (Ed.), The Politics of Life in Schools, Sage, Newbury Park, pp. 1 - 18.

Blase, J. and Anderson, G.L. (1995), The Micropolitics of Educational Leadership: From Control to Empowerment, Teachers College Press, New York.

Blase, J. and Blase, J. (2002a), "The dark side of leadership: teacher perspectives of principal maltreatment", Educational Administration Quarterly, Vol. 38 No. 5, pp. 671-727. 
Blase, J. and Blase, J. (2002b), "The micropolitics of instructional supervision: a call for research", Educational Administration Quarterly, Vol. 38 No. 1, pp. 6-44.

Bolman, L.G. and Deal, T.E. (2008). Reframing Organizations: Artistry, Choice and Leadership, 4th ed., Jossey-Bass, San Francisco.

Crow, G.M. and Weindling, D. (2010), "Learning to be political: new English headteachers' roles", Educational Policy, Vol. 24 No. 1, pp. 137-158.

Cuban, L. (1988), The Managerial Imperative and the Practice of Leadership in Schools, State University of New York Press, Albany.

Davis, S. (1998), "Superintendents' perspectives on the involuntary departure of public school principals: the most frequent reasons why principals lose their jobs", Educational Administration Quarterly, Vol. 34 No. 1, pp. 58-90.

de Jong, E.J., Gort, M. and Cobb, C.D. (2005), "Bilingual education within the context of English-only policies: three districts' responses to Question 2 in Massachusetts", Educational Policy, Vol. 19 No. 4, pp. 595-620.

Fink, D. (2005), "Developing leaders for their future not our past", in Coles, M.J. and Southworth, G. (Eds.), Developing Leadership: Creating the Schools of Tomorrow, McGraw-Hill, New York, pp. 1-20.

Fraatz, J.M.B. (1989), "Political principals: efficiency, effectiveness, and the political dynamics of school administration", International Journal of Qualitative Studies in Education, Vol. 2 No. 1, pp. 3-24.

Honig, M.I. (2006), "Complexity and policy implementation: challenges and opportunities for the field", in Honig, M.I. (Ed.), New Directions in Policy Implementation: Confronting Complexity, State University of New York, Albany, pp. 1-23. 
Kirst, M.W. and Wirt, F.M. (2009), The Political Dynamics of American Education, 4th ed., McCutchan Publishing Corporation, Richmond, CA.

Koyama, J. (2011), "Principals, power, and policy: enacting 'Supplemental Educational Services'", Anthropology and Education Quarterly, Vol. 42 No. 1, pp. 20-36.

Levinson, B.A.U., Sutton, M. and Winstead, T. (2009), "Education policy as a practice of power: theoretical tools, ethnographic methods, democratic options", Educational Policy, Vol. 23 No. 6, pp. 767-795.

MacLure, M. (2003), Discourse in Educational and Social Research, Open University Press, Philadelphia, PA.

Malen, B. and Cochran, M.V. (2008), "Beyond pluralistic patterns of power: research on the micropolitics of schools", in Cooper, B.S., Cibulka, J.G. and Fusarelli, L.D. (Eds.), Handbook of Education Politics and Policy, Routledge, New York, pp. $148-178$.

Malen, B. and Ogawa, R.T. (1988), "Professional-patron influence on site-based governance councils: a confounding case study", Educational Evaluation and Policy Analysis, Vol. 10 No. 4, pp. 251-270.

Marsh, J. (2012), "The micropolitics of implementing a school-based bonus policy: the case of New York City's Compensation Committees", Educational Evaluation and Policy Analysis, Vol. 34 No. 2, pp. 164-184.

McGinn, A. (2005), "The story of 10 principals whose exercise of social and political acumen contributes to their success", International Electronic Journal for Leadership in Learning, Vol. 9 No. 5, available at: http://people.ucalgary.ca/ huartson/iejll/volume9/mcginn.htm (accessed 27 August 2012). 
Mentz, K., Webber, C.F., and van der Walt, J.L. (2010), "Novice principals from Canada and South Africa share their experiences", Education as Change, Vol. 14 No. 2, pp. $155-167$.

Miles, M.B. and Huberman, A.M. (1994), Qualitative Data Analysis: An Expanded Sourcebook, SAGE Publications, Thousand Oaks, CA.

Normore, A.H. (2004), "Recruitment and selection: meeting the leadership shortage in one large Canadian school district", Canadian Journal of Educational Administration and Policy, Vol. 30, available at: http://www.umanitoba.ca/publications/cjeap/articles/normore.html (accessed 29 August 2012).

Ontario College of Teachers (2009), Principal's Qualification Program 2009, available at: http://www.oct.ca/additional_qualifications/principals_qualification/pdf/principals _qualification_program_e.pdf (accessed 27 August 2012).

Ontario Ministry of Education (2009a), Leadership Development, available at: http://www.edu.gov.on.ca/eng/policyfunding/leadership/actionPlan.html (accessed 29 August 2012).

Ontario Ministry of Education (2009b), Ontario's Equity and Inclusive Education Strategy, available at: http://www.edu.gov.on.ca/eng/policyfunding/equity.pdf (accessed 29 August 2012).

Ontario Ministry of Education (2009/2011), Character Development Initiative, available at: http://www.edu.gov.on.ca/eng/literacynumeracy/character.html (accessed 27 August 2012).

Ontario Ministry of Education (2010), Education Facts, available at: http://www.edu.gov.on.ca/eng/educationFacts.html (accessed 29 August 2012). 
Ontario Ministry of Education (2012), Results-based Plan 2011/12, available at: http://www.edu.gov.on.ca/eng/about/annualreport/\#1 (accessed 30 August 2012).

Ozga, J. (2000), Policy Research in Educational Settings: Contested Terrain, Open University Press, Buckingham, UK.

Ricci, C. (2004), "The case against standardized testing and the call for a revitalization of democracy", Review of Education, Pedagogy, and Cultural Studies, Vol. 26 No. 4, pp. 339-361.

Ryan, J. (2010), "Promoting social justice in schools: principals' political strategies", International Journal of Leadership in Education: Theory and Practice, Vol. 13 No. 4, pp. 357 - 376.

Smith, D. (2010), "Developing leaders using case inquiry", Scholar-Practitioner Quarterly, Vol. 4 No. 2, pp. 104-124.

Spillane, J.P., Reiser, B.J. and Reimer, T. (2002), "Policy implementation and cognition: reframing and refocusing implementation research", Review of Educational Research, Vol. 72 No. 3, pp. 387-431.

Starr, K. (2011), "Principals and the politics of resistance to change", Educational Management Administration and Leadership, Vol. 39 No. 6, pp. 646-660.

The Institute for Education Leadership (2008), Putting Ontario's Leadership Framework into Action: A Guide for School and System Leaders, available at: http://live.iel.immix.ca/storage/2/1284580690/FrameworkAction.pdf. (accessed 29 August 2012).

Winton, S. (2010), "Character development and critical democratic education in Ontario, Canada", Leadership and Policy in Schools, Vol. 9 No. 2, pp. 220-237.

Young, J., Levin, B. and Wallin, D. (2008), Understanding Canadian schools: An Introduction to Educational Administration, Nelson Education, Toronto, ON. 
Zaretsky, L. (2003), Parent Advocates' and Principals' Perspectives on Their

Interactions in Special Education, Ph.D. Dissertation, University of Toronto.

Zaretsky, L., Moreau, L. and Faircloth, S. (2008), "Voices from the field: school leadership in special education, Alberta Journal of Educational Research, Vol. 54 No. 2, pp. 161-177. 